\title{
Improve "national training plan" quality of primary and secondary school English teacher training Approaches
}

\author{
Lijun Wang \\ Hubei University of Science and Technology \\ Xianning, Hubei 437100, China
}

\begin{abstract}
Improving the quality of teachers directly affects the quality of teaching, namely the quality of talents. The basic purpose of education is to nurture talent, so the teacher quality will have a very important role. National training program is a national key project to upgrade the quality of teachers, the factors that affecting the effectiveness of the implementation of national training program has among trainees, organizers, policy development and implementation of distance exist. In response to these should propose an effective way to enhance the quality of training.
\end{abstract}

Keywords- national training program teacher training quality approach

\section{START NATIONAL TRAINING PROGRAM}

National training program stands for "national primary and secondary school teachers training program", its implementation is that "Long-term Education Reform and Development Plan (2012--2020)" important implementation and improve primary and secondary school teachers, especially in rural areas teachers an important measure of overall quality. The purpose of national training program is for primary and secondary school teachers in rural teachers, especially in central and western areas of training, thus contributing to the reform of teacher professional development and basic education. [1] National training program is divided into teacher training programs and the backbone of the rural Midwest into two categories primary and secondary teacher training programs. Among them, the demonstration of the training program, including primary and secondary school teachers backbone of teacher training and distance training two components: the backbone of the rural Midwest teacher training programs, including replacement of full-time training in rural primary and secondary school teachers in rural primary and secondary school teachers in the short-term intensive training, rural teachers remote training three subprojects.

National training program is scheduled in 2010. Initiated by the central government invested 550 million yuan to implement, in order to ensure the quality of implementation, the Ministry of Education through the review and selection, selection of Peking University, Guangzhou University,
Beijing Normal University, East China Normal University, Nanjing Normal University, South China Normal University, Shaanxi Normal University Jiangxi Normal University, Xuzhou Normal University for contractors to start the national training program. It is purpose is to develop the new requirements of the new era of education reform proposed by teachers, aimed to adapt to conditions, and enhance international competitiveness, and promote balanced development of compulsory education, promote basic education reform, improve the overall quality of education. [2] The original mission of training school teachers are local, however, the significance lies a good example to the local implementation, the first focus group of high-quality resources to train a "seed" teachers. So that this group of teachers in the frontline work can play a key role model, and in the training process, summarize integrated approach to quality resources and seek innovative training models and methods for the local implementation of teacher training a good example.

\section{DEFECT ANALYSIS OF NATIONAL TRAINING PROGRAMS}

I believe that. There are three factors that affecting the effectiveness of implementation of the national training program: Refers to the primary and secondary classroom teachers across all levels: Second organizers. Refers to assume major universities and training courses are taught by: Third, there is a certain distance between policy formulation and implementation.

\subsection{Restriction trainees}

From the current national training program trainees constituted, it is selected by the district's schools layer by layer. This is very unscientific way. From the selected result, the ultimate level selected by the school teachers are mostly out has the following two characteristics: First, the process selected did not respect teachers' subjective needs [3]: The second is selected as an English teacher is not the task of teaching. Such detail leads trainees not interested in studying in participating in the training process, often leave, and some even just to report, occupy places do and not learn. Such selected screening trainee collective must be a not good start for the country itself. 


\subsection{Organizers restrictive}

Organizers national training program are qualified by bidding forms. It are reasonable scientific theory. However, in practice, faculty winning institutions, professional level and training needs and can not achieve a good butt. From the part of organizers, first, must to have a high level of teacher training disciplines. This is to ensure the quality of training of core strength. Furthermore, we should have a high-level management team. To good prepare the training logistics. For example, among subjects in the training, some schools will be more of a specialty subjects, relatively rich resources of their curriculum, teacher resources, teaching methods and models are highly effective, but resources are very farfetched offer other subjects, so bidders in the tender should seriously consider their strengths and weaknesses, and must not blind for some other interests tender.

\subsection{There is a certain distance between policy formulation and implementation}

Good training results must come from a good evaluation system. Effective evaluation system will improve the quality of training and obtain efficient training effect. Now the passage of the evaluation form is just a satisfaction by participating teachers to fill after the training. Not fully reflect the quality of the training. But can not for the future training of accumulated experience, make information feedback. Trainees have the following characteristics:

First, Those who was sent to participate in the training are full of expectations. They want to learn something and hold the confidence and determination; hope can be promoted from a brief training. Second, most of them can understand and analyze their own deficiencies in the teaching process of and know the crux of the problem, clear understanding of things to learn of their training course. Third, in the training process, most teachers think that the training courses designed units are not able to meet their own needs, the course is unattractive; the instructor can not be done targeted teaching. Fourth, at the end of the training, the majority of trainees in the training certainly learned simultaneously. Training to bring their own promotion and not satisfied that there is no purpose to achieve their trainees, mainly due to courses offered by the organizers themselves.

Learned that the gap between policy and implementation of this afterwards. I believe that the organizers of China's current national training program is among of the implementation of the process of leading the party, what organizers to offer what trainees learn, trained teachers who can only follow the footsteps of the organizers, according to the need for fill. Obviously, this reality is not central desired results in the formulation of policy, only the relationship between the two into each other is reasonable when the active side. Needed determines teaching, teach the necessary improvements, the new desired drive new teach, teach new reform needed, both to spiraling trend, helping each other the way forward, and ultimately achieve mutual progress.

\section{WAYS TO ENHANCE THE NATIONAL TRAINING PROGRAM}

National training program appeared a series of problems in the process of implementing. It requires us to give the right solution, I proposed the following to improve." National training plan "quality primary and secondary school English teacher training approaches:

\subsection{Select trainees based on the intensity of the training needs}

We must understand the objective of the training program. Beginning of the national training program is the choice of trained teachers, the "training who" question. The real problem lies in the schools and teachers of English teachers selected. I think this is a two-way choice. School how to elect school English teacher and English teachers how to recommend himself. For the school, it should form an active learning environment for teachers to attend training pride, not considered to be helping the school to complete the task. Then select those who actually truly necessary training school teachers based on teaching and teachers' personal circumstances. Who should further enhance the strength of teaching teachers: Personally for teachers, we must first have the enthusiasm for further learning. It is let them to establish a sense of crisis, only to continually learn, to let students learn better. Second, teachers must be able to clearly self-evaluation, self-awareness, analysis of personal strengths and weaknesses in terms of expertise in the reserves, teaching skills application, teaching philosophy, etc., to choose combined with training content, obtain, or to give up training opportunities. [4] In this regard, I believe, should be implemented" the teacher individual application system" and should be established, "the national provinces and one city a county school" coherent application integration mechanism, so that the teachers who need to train can participate in the training, each training places can play a role, do not waste each sub-fund the country.

\subsection{To enhance the quality of training organizers}

The organizers of national training program is consists of two principal. First, national policy makers, the second is to undertake training major task in Normal Universities. From the point of view of national policy development side, national training program to reflect the kind of public and social values, its essence is the embodied functions of government to maintain social justice. Government in order to promote the construction and development of primary and secondary school teachers in rural areas, it is need to equitable distribution of teacher training, which is the national training program of significance. Currently, as to the national training program bearers, choose Normal Universities, the government adopted a bidding mechanism, fair and competitive, capable of high-quality selection of training units, reaching a virtuous combination of training and discipline in universities. And the bear inside the university also has formed a department responsible for 
national training program, which made rigid protection to the implementation of national training program. As the department who responsible for national training college project, the first thing to do the analysis of research to understand the trainees needed, and then set up course for the trainee characteristics and original curriculum, course content and format required rationalization, diversification, then they should select the best teachers teaching. In this way, we can ensure attractive programs to get the best training effect, enhance the effectiveness of national training program.

\subsection{Strengthening the practicality and effectiveness of training.}

In training for the project implementation process of the existence of a lack of practical training and scientific problem, its solution to the problem is to strengthen the practicality and effectiveness in training and curriculum resources, such as strengthening the English speech training, learning English courseware, enter the English language and cultural knowledge, micro-teaching and teaching trainees how to obtain information through the network resources. Now we know that do the training necessary is to allow trainers to see the change before and after training. Whether training in local training or in national training, after participating issue is resolved in the training is important. To do this, you must set the training content with the practicality and effectiveness, and effectively close to the actual work of trainees, absolutely can help trainees to solve their practical difficulties and problems, as well as implement the principle of combining theory with practice. Otherwise, all the formality of the training will waste a lot of manpower, material and financial resources, and ultimately become a piece of paper talk.

\subsection{Sound expert appraisal mechanism.}

The introduction of any project or policy not only has a scientific basis or guidance, but also has the relevant experts and scholars to give timely comments, so as "National training plan". The establishment and implementation of the "national training plan" is the theory, practice, and policy number of studies the interaction process. Teachers College and School English teacher realized the mutual exchanges and cooperation. However, the experience those college English teachers for primary and secondary school English teachers and improvement measures also need to have timely coaching and evaluation related to the education sector and relevant experts and scholars. Therefore, a good expert assessment mechanism is the key factor to ensure that teacher training methodical, scientific and orderly consult.

\section{CONCLUSION}

Along with the centre attached great importance to quality of primary and secondary school English teachers, especially in rural primary and secondary teachers, the construction of teachers has become an important part. "National training plan" as a national teacher training program, which is designed to be comprehensive, including specific training objectives and training content in line with national requirements, have a positive impact and guidance effect to update the concept of education of teachers, improve teaching skills. Of course, such a huge scale of training, the implementation process will have some deficiencies. However, if we can put forward questions and solve problems, I believe that any things will be good direction of sustainable development.

The implementation of the "national training plan" reflects the entire country to grasp the basic education, improve the quality of basic education teachers' attention. By "national training plan" we explored a new model of teacher training, developed and enriched the quality of teacher training resources, construction of a number of teacher training focused on base, created more and more for primary and secondary school English teachers, especially offer good training opportunities for teachers in central and western rural, provided a high level of quality training services. In short, the country training program is a strong program to teach, strongman, national policy powers, from the start of training high-quality teachers. It is a long-term plan to improve the quality of the people. In the process of implementing, every step must have a clear quality orientation, quality in every detail in order to ensure the overall quality, can tend to be consistent with the original purpose that making the country a veritable training program.

\section{Acknowledgements}

One of initial results of National Training Program --based on the dynamic needs of English teachers in rural primary and secondary schools based on the analysis of fulltime training program of replacement, supported by National Social Science Fund Project (Grant Number: 13BYY073 ).

\section{References}

[1] Feng Guorui. <Teacher training strategy under the "national training plan" background $>[\mathrm{J}]$. Jiao Zuo Teachers College, 2012, (3): 63-65.

[2] The Verdict. <The value On the "national training program,"> [J]. Teacher Education Research, 2010, (11): 3-9.

[3] Su Xiao. <Explore the current development "national training plan"> [J]. Science and the public, 2013, (3): 150-151.

[4] LI Senlin, Yan Guizhi. <Factors affecting the quality of education and training and the control strategy> $[\mathrm{J}]$. Continuing Education, 2005, (19): 46-47. 